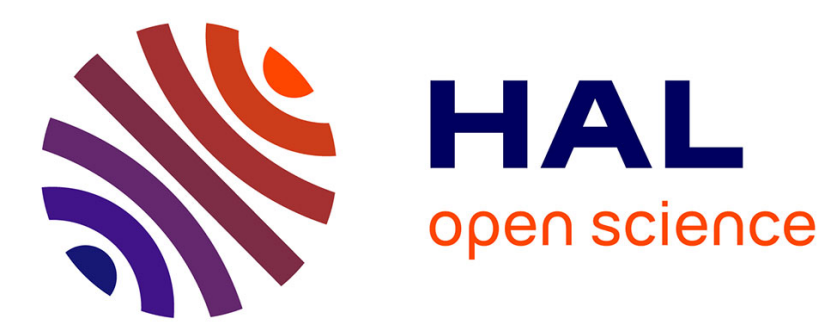

\title{
Brain germinoma presenting as a first psychotic episode in an adolescent male
}

\author{
Juan Undurraga, Inmaculada Baeza, Marc Valentí, M. L. Lázaro
}

\section{To cite this version:}

Juan Undurraga, Inmaculada Baeza, Marc Valentí, M. L. Lázaro. Brain germinoma presenting as a first psychotic episode in an adolescent male. European Child and Adolescent Psychiatry, 2010, 19 (9), pp.741-742. 10.1007/s00787-010-0107-7 . hal-00581532

\section{HAL Id: hal-00581532 \\ https://hal.science/hal-00581532}

Submitted on 31 Mar 2011

HAL is a multi-disciplinary open access archive for the deposit and dissemination of scientific research documents, whether they are published or not. The documents may come from teaching and research institutions in France or abroad, or from public or private research centers.
L'archive ouverte pluridisciplinaire HAL, est destinée au dépôt et à la diffusion de documents scientifiques de niveau recherche, publiés ou non, émanant des établissements d'enseignement et de recherche français ou étrangers, des laboratoires publics ou privés. 


\section{Case Report:}

\section{Brain germinoma presenting as a first psychotic episode in an adolescent male}

Column title: Brain tumor as first psychotic episode.

Authors:

Undurraga, Juan MD

Department of Psychiatry, Institute of Neuroscience, Hospital Clínic de Barcelona, Barcelona, Spain.

Baeza, Inmaculada MD, PhD

Department of Child and Adolescent Psychology and Psychiatry, Institute of Neuroscience, Hospital Clínic de Barcelona, Barcelona, Spain; Centro de Investigación Biomédica en Red (CIBERSAM).

Valentí, Marc MD

Department of Psychiatry, Institute of Neuroscience, Hospital Clínic de Barcelona, Barcelona, Spain.

Lázaro, ML MD, PhD

Department of Child and Adolescent Psychology and Psychiatry, Institute of Neuroscience, Hospital Clínic de Barcelona, Barcelona, Spain; Centro de Investigación Biomédica en Red (CIBERSAM).

Corresponding autor: Juan Undurraga

Email: jundurra@clinic.ub.es

Phone number: (34) 932275477

Fax number: (34) 932279876

Adress : Hospital Clínic de Barcelona, Servicio de Psiquiatría (Escalera 9, planta 6).

Calle Villarroel, 170; Barcelona.

Postal Code: 08036

Word count: 851 .

Disclosure: The authors report no conflicts of interest. 
Sir:

The association between brain lesions and psychiatric disorders has long been known. A wide variety of these syndromes have been reported since Dr John Harlow's description of his patient Phineas Gage more than 150 years ago [4]. These syndromes have included personality changes, psychosis, obsessive-compulsive symptoms, depression, anxiety disorders, mania, cognitive deterioration and anorexia nervosa $[1,5,6]$. Most reports describe tumors of the frontal or temporal lobes, and very few discuss the psychiatric sequelae of tumors primarily affecting subcortical structures $[7,13]$. Moreover, there have been few reports in the pediatric literature concerning this phenomenon $[2,3,9]$.

We report on a well-adjusted 17-year-old adolescent with no prior psychiatric history who was brought by his parents to our psychiatric emergency room. He presented with a 3 month history of progressive social withdrawal, apathy, lack of drive and deterioration of academic achievement. During the month prior to consultation, he also showed neglect in personal cleanliness and daytime somnolence. There was no significant medical or developmental history, and he was receiving no medication. No family history of mental illness was reported.

At clinical admission, the patient was conscious, attentive and well-oriented in terms of place and person but with respect to time he could only identify the year. He had short term memory loss, was perplexed, exhibited psychomotor inhibition and maintained poor eye contact. His affect was flattened and incongruent in quality, with unprovoked smiles. He was apathic and presented loss of drive. He showed poverty of content of speech, and spoke in an unfluent, low and unexpressive tone. Thought processes were retarded and overly concrete. He was not delusional, but described hearing noises and voices calling his name and sporadic visual sensations on the edge of his visual field which he described as "wing flutters". There were no suicidal thoughts or plans. He had daytime hypersomnolence. He demonstrated little insight into his condition but accepted hospitalization with indifference. The Positive and Negative Syndrome Scale (PANSS) was administered and the scores were 13 on PANSS positive, 36 on PANSS negative, 33 on PANSS general and 82 on PANSS total. Physical and neurological examination revealed a limitation in supraversion of the eyes, with no other significant abnormalities. Serum chemistry and complete blood count was normal. A brain magnetic resonance image (MRI) revealed a heterogeneous cerebral mass, with necrotic and hemorrhagic areas, infiltrating the thalamus, mesencephalon, right 
mammillary tubercle, interventricular septum, and corpus callosum with mild perilesional edema extending to both internal capsules. Secondary ventricular dilatation was also observed.

The patient was transferred to the neurosurgery unit where a cerebral biopsy and ventriculoperitoneal derivation was performed. The biopsy revealed an intracranial germinoma with syncitiotrophoblast cells. The patient had a new surgical intervention because of hydrocephalic signs and was subsequently transferred to the oncology department to receive chemotherapy. A week later, he presented a brain stem haemorrhage and died.

\section{Discussion}

This is a case of an adolescent male with negative and positive psychotic symptoms who had an intracranial germinoma. Germinomas, a type of germ cell tumor, reach a peak incidence in the second half of the second decade and affect males ten times as often as females [9]. Up to $35 \%$ of patients will be asymptomatic for more than six months [10]. In general, germinomas carry an excellent prognosis with most series suggesting five-year progression free survival rates and a cure in well over $90 \%$ of patients [10]. However, prognosis is highly dependent on the histological subtype of the tumor present. Syncytiotrophoblastic tumors tend to relate to less favorable outcome, although this has no been found to be the case in all series [10].

Our patient had prominent psychiatric symptoms that made us suspect a new-onset psychosis. However, in the neurological examination, he showed a limitation in the supraversion of the eyes. This limitation is part of the dorsal midbrain syndrome described by Henri Parinaud in the late nineteenth century [11]. This syndrome usually results from damage to premotor pathways for binocular upward gaze in the dorsal mesencephalon [8]. It may be caused by extrinsic or intrinsic lesions, with hydrocephalus being a common aetiology [8]. Additionally, the patient could have had cerebellar pathways involvement, as suggested by the cerebellar cognitive affective syndrome $[12,15]$ he presented. This syndrome, described by Schamahmann and colleagues [15], supposes that the cerebellum participates in the organization of higher order function. Lesions that involve the cerebellum or its pathways can manifest as impairment of executive functions, difficulties with spatial cognition, personality change with blunting of affect or disinhibited and inappropriate behaviour and language deficits including agrammatism and dysprosodia.

Patients with brain tumors may present with a wide variety of psychiatric symptoms, and have minimal or no neurological symptoms or signs. These symptoms are very unspecific. A recent 
review of the literature concluded that neither tumor type nor location is associated with any particular psychiatric manifestation [6].

Early detection can have a direct influence on treatment options and outcome, so a high degree of awareness is recommended. We think it is also important to assess patients that present with a first episode of psychosis with neuroimaging tools to rule out the possibility of brain lesions.

\section{References}

[1] Bunevicius A, Deltuva VP, Deltuviene D, Tamasauskas A, Bunevicius R (2008).Brain lesions manifesting as psychiatric disorders: eight cases. CNS Spectr. 13:950-8.

[2] Craven C (2001). Pineal germinoma and psychosis. J Am Acad Child Adolesc Psychiatry. 40(1):6.

[3] Gamazo-Garrán P, Soutullo CA, Ortuño F (2002). Obsessive-compulsive disorder secondary to brain dysgerminoma in an adolescent boy: a positron emission tomography case report. $\mathrm{J}$ Child Adolesc Psychopharmacol.12(3):259-63.

[4] Harlow JM (1848). Passage of an iron rod through the head. Boston Medical and Surgical Journal; 39:389-393.

[5] Madhusoodanan S, Danan D, Brenner R, Bogunovic O (2004). Brain tumor and psychiatric manifestations: a case report and brief review. Ann Clin Psychiatry. 16:111-3.

[6] Madhusoodanan S, Danan D, Moise D (2007).Psychiatric manifestations of brain tumors: diagnostic implications. Expert Rev Neurother. 7(4):343-9. Review.

[7] Martínez-Lage JF, Pérez-Espejo MA, Esteban JA, Poza M (2002). Thalamic tumors: clinical presentation. Childs Nerv Syst. 18(8):405-11.

[8] Miller NR (2006). Late improvement in upward gaze in a patient with hydrocephalus related Parinaud dorsal midbrain syndrome. Br J Ophthalmol. 90(1):123.

[9] Mordecai D, Shaw RJ, Fisher PG, Mittelstadt PA, Guterman T, Donaldson SS (2000). Case study: suprasellar germinoma presenting with psychotic and obsessive-compulsive symptoms. J Am Acad Child Adolesc Psychiatry. 39:116-9.

[10] Packer RJ, Cohen BH, Cooney K (2000). Intracraneal germ cell tumors. Oncologist. 5(4):31220. Review.

[11] Pearce JM (2005). Parinaud's syndrome. J Neurol Neurosurg Psychiatry. 76(1):99.

[12] Riva D, Giorgi C (2000). The cerebellum contributes to higher functions during development: evidence from a series of children surgically treated for posterior fossa tumours. Brain. 123 ( Pt 5):1051-61.

[13] Rushing EJ, Sandberg GD, Judkins AR, Vezina G, Kadom N, Myseros JS, Packer RJ, Santi M (2006).Germinoma: unusual imaging and pathological characteristics. Report of two cases. J Neurosurg. 104(2 Suppl):143-8. 
[14] Schmahmann JD, Sherman JC (1998). The cerebellar cognitive affective syndrome. Brain. 121 ( Pt 4):561-79.

[15] Schmahmann JD, Weilburg JB, Sherman JC (2007). The neuropsychiatry of the cerebellum insights from the clinic. Cerebellum. 6(3):254-67. Review. 